\title{
Open preperitoneal mesh repair of recurrent inguinal hernia
}

\author{
K. M. Katri
}

Received: 17 October 2009 / Accepted: 29 October 2009 / Published online: 19 November 2009

(C) Springer-Verlag 2009

Dear Sir,

Since the beginning of laparoscopic hernia repair in the early 1990s, to fix or not to fix the mesh has been a dilemma. Not fixing the mesh can lead to recurrence of the hernia secondary to displacement of the mesh, contraction of the mesh or bunching-up of the mesh (a phenomenon that has been referred to as meshoma) with uncovering of a hernia defect $[1,2]$. If the mesh is not to be fixed, Wantz [3] recommends Mersilene, because it is soft, conforms to the complex curves of the pelvis, and stays in place. Opponents of mesh fixation cite the risk of nerve injury and argue that mesh fixation is unnecessary to achieve prolonged mesh placement and successful repair [4-6]. To resolve this dilemma, some authors have suggested fixation of the mesh by fibrin glue [7]. On the basis of current evidence, I might agree on not fixing the mesh in primary hernia repair, but in recurrent hernia (after anterior repair) I would not accept any risk of recurrence, as any possible subsequent surgery of either anterior and posterior repair would be difficult because of scarring. Using tacks for fixation can reduce the time, but is certainly more costly and might be associated with an increased incidence of postoperative pain.

\section{References}

1. Lowham AS, Filipi CJ, Fitzgibbons RJ et al (1997) Mechanisms of hernia recurrence after preperitioneal mesh repair: traditional and laparoscopic. Ann Surg 225:422-431

2. Amid PK (2004) Radiologic images of meshoma: a new phenomenon causing chronic pain after prosthetic repair of abdominal wall hernias. Arch Surg 139:1297-1298

3. Wantz GE (1994) Preperitoneal hernioplasty with unilateral giant prosthetic reinforcement of the visceral sac. Contemp Surg 44:8389

4. Beattie GC, Kumar S, Nixon SJ (2000) Laparoscopic total extraperitoneal hernia repair: mesh fixation is unnecessary. J Laparoendosc Adv Surg Tech A 10:71-73

5. Moreno-Egea A, Torralba Martinez JA, Morales Cuenca G, Aguayo Albasini JL (2004) Randomized clinical trial of fixation vs nonfixation of mesh in total extraperitoneal inguinal hernioplasty. Arch Surg 139:1376-1379

6. Taylor C, Layani L, Liew V, Ghusn M, Crampton N, White S (2008) Laparoscopic inguinal hernia repair without mesh fixation, early results of a large randomised clinical trial. Surg Endosc 22:757-762

7. Katkhouda N, Mavor E, Friedlander MH et al (2001) Use of fibrin sealant for prosthetic mesh fixation in laparoscopic extraperitoneal inguinal hernia repair. Ann Surg 233:18-25

\section{K. M. Katri}

199 Porsaid St, Sporting, Alexandria, Egypt

\section{K. M. Katri ( $\square)$}

Department of General Surgery, Faculty of Medicine,

University of Alexandria, Alexandria, Egypt

e-mail: kkatry@hotmail.com 